\title{
SURFACE INTEGRITY STUDY OF CREEP-FEED GRINDING
}

\author{
Marin Gostimirovic ${ }^{1 *}$, Milenko Sekulic ${ }^{1}$, Dragan Rodic ${ }^{1}$ \\ ${ }^{1}$ University of Novi Sad, Faculty of Technical Sciences, Department of Production Engineering, Serbia
}

\begin{abstract}
:
This paper reports on the research results of surface integrity of the workpiece in creep-feed grinding on the high speed tool steel. The creepfeed grinding is an advanced abrasive process widely used in industry of complex and heavy engineering products. An experimental investigation of the fundamental characteristics of surface metallurgy and surface roughness is carried out. The metallurgical properties were determined by an optical microscope, and through: microstructure, microhardness, cracks and burns. The surface roughness was determined with multiple important roughness parameters through scanning the surface topography (roughness average, mean roughness depth, maximum roughness depth and profile bearing length ratio). The results show that the grinding surface integrity is acceptable with good material removal rate, so that the creep-feed grinding process is an excellent choice for efficient and quality material removal. However, creep-feed grinding is not suitable for the final machining because of the possible metallurgical alterations due to high thermal load.
\end{abstract}

\section{ARTICLE HISTORY}

Received: 09.05.2020.

Accepted: 15.09.2020.

Available: 30.09.2020.

\section{KEYWORDS}

Advanced grinding process, Surface metallurgy, Surface layer properties, Surface topography, Surface roughness

\section{INTRODUCTION}

Global manufacturing industry is facing a number of key challenges on a daily basis. Productivity, quality, reliability, flexibility, responsiveness, innovation and sustainability are the most important demands confronting the market oriented manufacturing systems. With the rapidly growing trends in deploying advanced components and products, only modern industrial systems shall be able to adjust their production process to all the complex challenges and demands.

Due to the aforementioned, along with the development of new product ranges, modern industrial concept implies permanent improvement of existing manufacturing technologies, as well as the introduction of new ones. In this context, there can be no doubt these technologies will remain important in the modern production, especially material removal processes. Basic advantages of the material removal processes are high quality and productivity with the ability to cope with difficult-to-machine materials and complex geometrical shapes of engineering components [1].

Grinding is considered one of the most important material removal processes in the manufacturing industry today. The main advantages of grinding process include good dimensional accuracy and high surface finish [2-4].

In the recent period, in addition to conventional multi-pass grinding technology, there has been an introduction of high-performance grinding processes, Fig.1. These grinding methods use higher cutting speeds and larger depths of cut in order to increase the low productivity which has been considered the main drawback of the multipass grinding operations. However, the highperformance grinding conditions considerably change the kinematics of cutting process [5-8].

High-speed grinding is characterized by lower cross-section of chip and shorter time of contact between the workpiece and abrasive particles, but with a more intense friction in the cutting zone [9]. In creep-feed grinding there is very long wheel/workpiece contact which leads to especially 
intense friction [10]. This rapid increased contribution of the friction leads to a more intense development of thermal energy in the contact zone $[11,12]$. The unwanted thermal effect, primarily in the workpiece material surface layer, represents the basic limitation for further development of highperformance grinding. For that reason, in the highperformance grinding a special attention is focused on surface integrity [13-15].

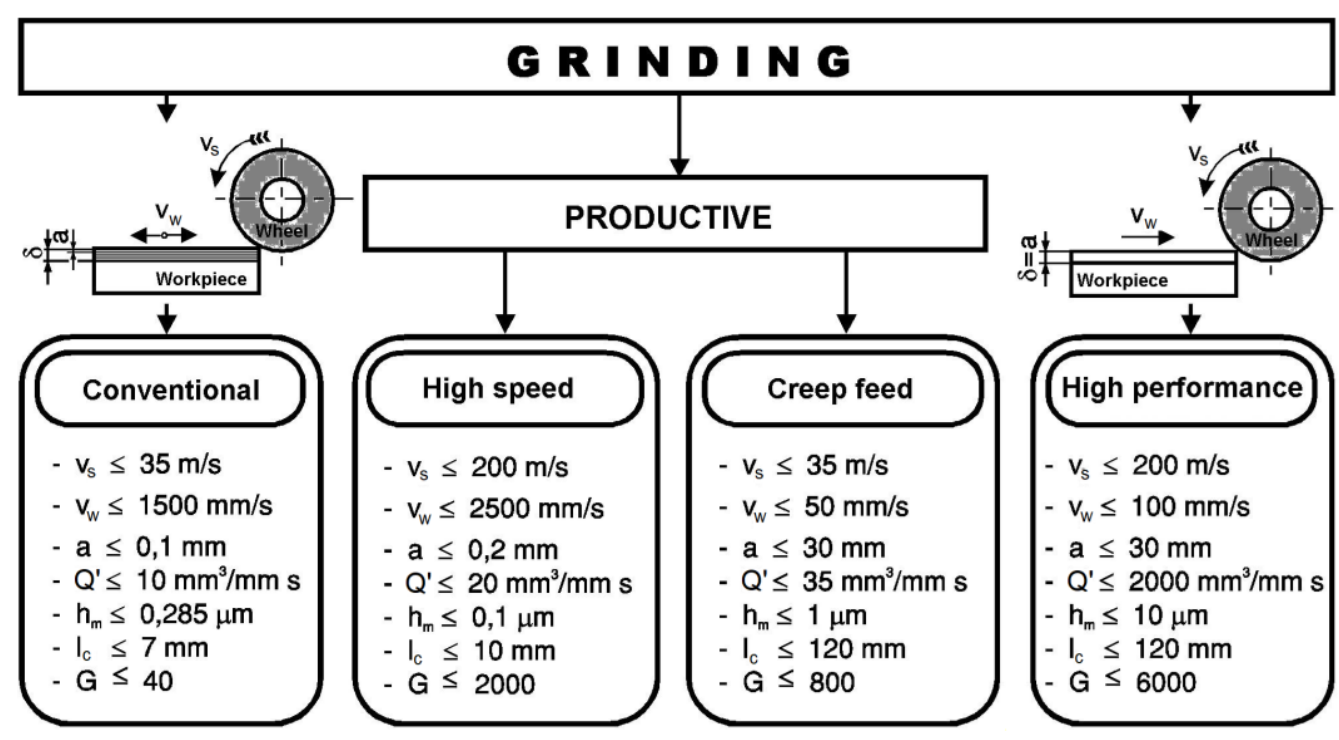

Fig. 1. Division and characteristics of grinding process

In the present work, the object of research is machining quality of the creep-feed grinding process. Since the main task of the creep-feed grinding is to achieve the required machining quality with as large productivity as possible, special attention is directed on the effect that machining conditions have on the change of the surface integrity. If the cutting conditions are poorly chosen, the overall effect can substantially diminish exploitation features of the grinding process. Therefore, in order to enable machining of the parts with a high surface quality, it is necessary to investigate the effect of the creepfeed grinding on the workpiece surface integrity.

\section{CREEP-FEED GRINDING PROCESS}

Creep-feed grinding has been used for over fifty years. The creep-feed grinding is a highly productive and accurate process of machining complex shapes and forms in a wide variety of challenging materials. Compared to a conventional process, the creep-feed grinding allows lighter passes and shorter cycle time. At the same time, the creep-feed grinding is characterized by a lower wheel wear and good surface roughness [16]. However, a prolonged time of contact between the wheel/workpiece, results in the generation of more intense heat release on the workpiece material surface layer.

\subsection{Mechanism of creep-feed grinding}

The creep-feed grinding process differs from the conventional multi-pass grinding. In creep-feed grinding, very low (creep) feed rate and extremely large depth of cut is used, generally with a profiled wheel [17]. In this context, the cutting process in creep-feed grinding is achieved through a large number of abrasive particles that catch a very thick layer of the material that is inserted in the space between the abrasive and in the pores of the grinding wheel. When the abrasive particles come out of the workpiece material, chips leave the pores under the influence of centrifugal force and the agent for cooling, lubrication and flushing.

The creep-feed grinding process itself is defined by the kinematic and geometric parameters, Fig. 2 . Kinematic parameters are: wheel cutting speed $v_{s}$ and workpiece feed rate $v_{w}$. The geometrical parameters are: wheel diameter $D_{s}$, depth of cut $a$, length of contact $I_{c}$ and average chip thickness $h_{m}$.

The length of contact of surface grinding is distance that grain actively exceeds from the moment of contact with the workpiece until exit from a contact:

$$
I_{c}=\sqrt{a \cdot D_{s}}
$$

The average chip thickness is the approximate thickness cut with abrasive grains, and determined by: 


$$
h_{m}=\frac{a \cdot v_{w}}{v_{s}}=\frac{Q^{\prime}}{v_{s}} .
$$

In the previous equation (2) it is observed that specific material removal rate:

$$
Q^{\prime}=a \cdot v_{w} .
$$

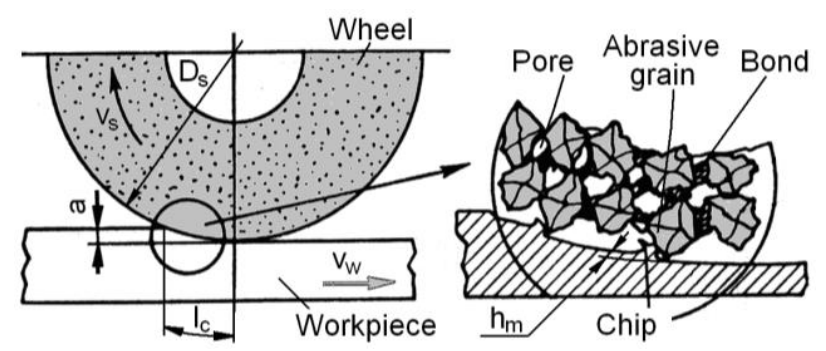

Fig. 2. Mechanism of creep-feed grinding

\subsection{Surface integrity of creep-feed grinding}

Surface integrity is presented with all of the parametes that define aspects existing on the surface and below the surface of the machined material. The surface integrity includes two important categories: surface topography (surface texture) and surface metallurgy (surface layer modification). The surface topography includes the physical geometry of the surface, respectively form, waviness and surface roughness. The surface metallurgy includes the properties of the material layer, respectively study of the nature of the local plastic deformation, microstructure, microhardness, residual stress, crack, burn, etc [18].

Surface topography describes surface roughness and other features associated with the geometry of the surface. The degree of surface roughness is the most important characteristic. The surface roughness is represented by a large number of irregularities on the surface incurred during material remove [19]. The most common surface roughness parameter is the roughness average, also know as arithmetic average of the surface. In grinding process, surface roughness is dependent of the workpiece material, size and orientation of the abrasive particles, machining conditions, etc.

Surface metallurgy is concerned primarily with the host of effects a machining process has on the subsurface altered material zone. The subsurface characteristics can be caused by mechanical, thermal or chemical energy, and affect the metallurgical and physical properties of the material. In grinding process, heat affected zone is the most important characteristic. The heat affected zone is an area of the base metal that has had property changes [20-22]. Fig. 3 shows the creep-feed grinding process with the performance characteristics and the surface integrity.

Fig. 3 shows the creep-feed grinding process with the performance characteristics and the surface integrity.

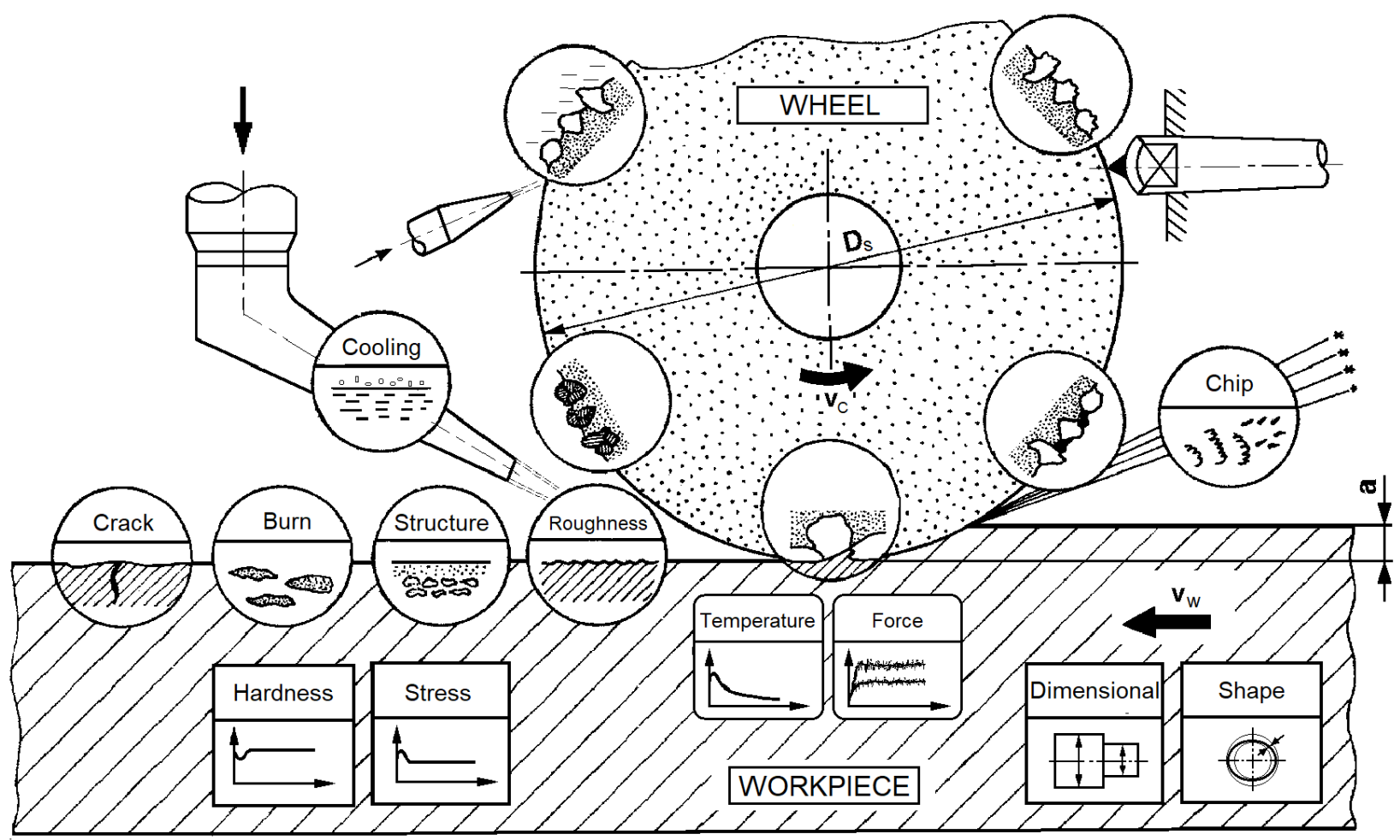

Fig. 3. Performance and surface integrity of creep-feed grinding process 


\section{EXPERIMENTAL PROCEDURES}

The experimental investigations were conducted on the 3-axis creep-feed grinding machine type CF 412 CNC by a manufacturer Majevica from Republic of Serbia, Fig.4. Main technical data of the grinding machine are as follows: table area $400 \times 1200 \mathrm{~mm}$, workpiece height max. $500 \mathrm{~mm}$, power $50 \mathrm{KW}$, wheel spindle speed $3000 \mathrm{rev} / \mathrm{min}$, table speed $20-20000$ $\mathrm{mm} / \mathrm{min}$, coolant flow $425 \mathrm{l} / \mathrm{min}$. Water-based coolant (emulsion $6 \%$ ) was used during the creepfeed grinding test with a flow rate of $175 \mathrm{l} / \mathrm{min}$.

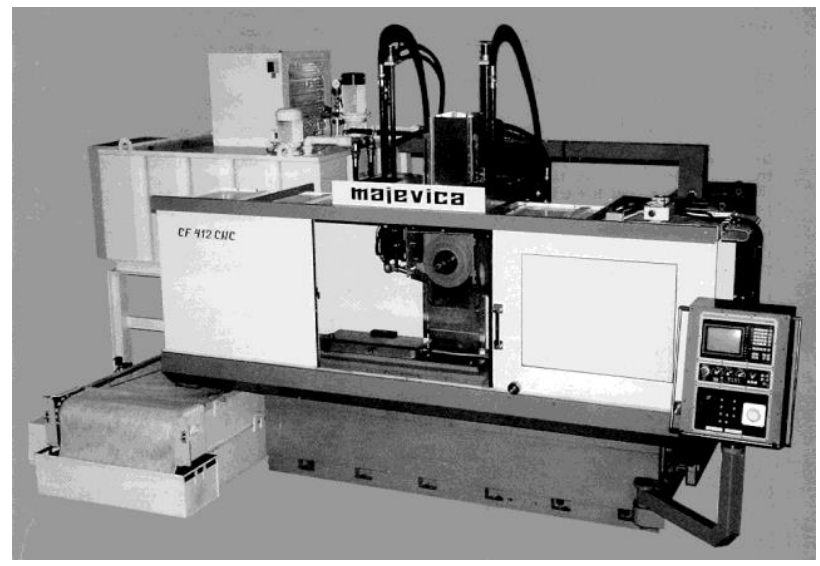

Fig. 4. CF 412 CNC creep-feed grinding machine

Based on the chosen material of the workpiece and the conditions of processing, the high porosity grinding wheels with the uniform characteristics were selected: Norton grinding wheel type 32A54 FV BEP, dimensions $400 \times 80 \times 127 \mathrm{~mm}$, respectively Winterthur grinding wheel type 53A80 F15V PMF, dimensions $400 \times 50 \times 127 \mathrm{~mm}$. The wheels are with high quality aluminium oxide abrasive grain, medium grain size, wheel hardness soft, open structure wheel, and made of ceramic binder. All of the experiments were conducted with sharp abrasive grains, and dressing is done with a diamond tool with a depth of dressing cut $0.01 \mathrm{~mm}$ and dressing feed rate $0.1 \mathrm{~mm} / \mathrm{rev}$.

Workpiece material used in the experimental setup was the high speed tool steel (HSS). Designation of the selected steel is DIN S 2-10-1-8 (W. Nr. 1.3247). This steel belongs to a group of highly-alloyed steel with a microstructure consisting of martensite and fine mixtures of primary and secondary carbides, Fig.5. The chemical composition of the test material was as follows: $1.08 \% \mathrm{C} ; 0.22 \% \mathrm{Si} ; 0.23 \% \mathrm{Mn} ; 0.014 \% \mathrm{P}$; $0.019 \%$ S; $4.1 \% \mathrm{Cr} ; 1.5 \% \mathrm{~W} ; 9 \% \mathrm{Mo} ; 1.1 \% \mathrm{~V}$ and $8 \% \mathrm{Co}$. The surface hardness on all samples was the range $66 \pm 1$ HRC. Experimental specimens consisted of tiles whose dimensions were $40 \times 20 \times 16 \mathrm{~mm}$.

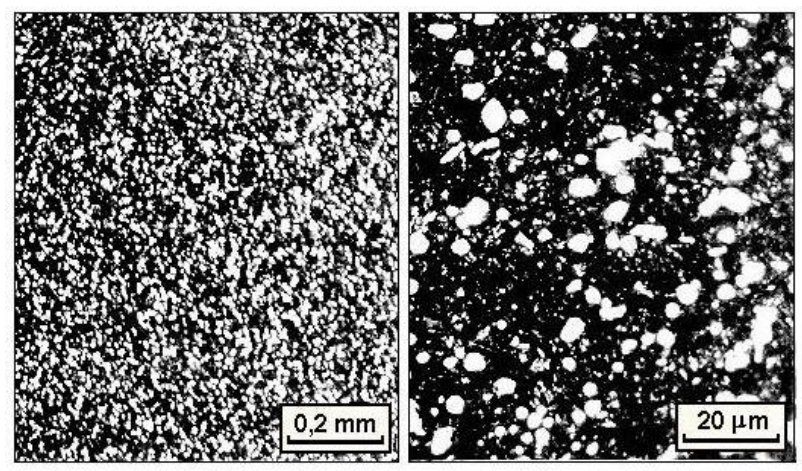

Fig. 5. Microstructure of workpiece material - HSS DIN 1.3247

The machining conditions are mean values of the depth of cut and the workpiece feed rate at a constant specific material removal rate $Q^{\prime}=2.5$ $\mathrm{mm}^{3} / \mathrm{mm} \mathrm{s}$. The range of the depth of cut was $a=$ 0.05 to $1 \mathrm{~mm}$, while the workpiece feed rate was chosen from the interval $v_{w}=2.5$ to $50 \mathrm{~mm} / \mathrm{s}$. The grinding wheel cutting speed was constant at $v_{s}=$ $30 \mathrm{~m} / \mathrm{s}$.

Surface metallurgy of the machined specimens was assessed by investigation of surface layer properties of the high speed tool steel in the creep-feed grinding. In this testing were conducted: metallographic examination of the microstructure, measuring the microhardness, and exploring cracks and burns. The surface metallurgy identification of the workpiece material surface layer after grinding was performed with an optical microscope with $200 \times$ magnification by a manufacturer Leitz Aristomet from Germany, Fig. 6 . Examinations were performed in a transverse section of the prepared samples.

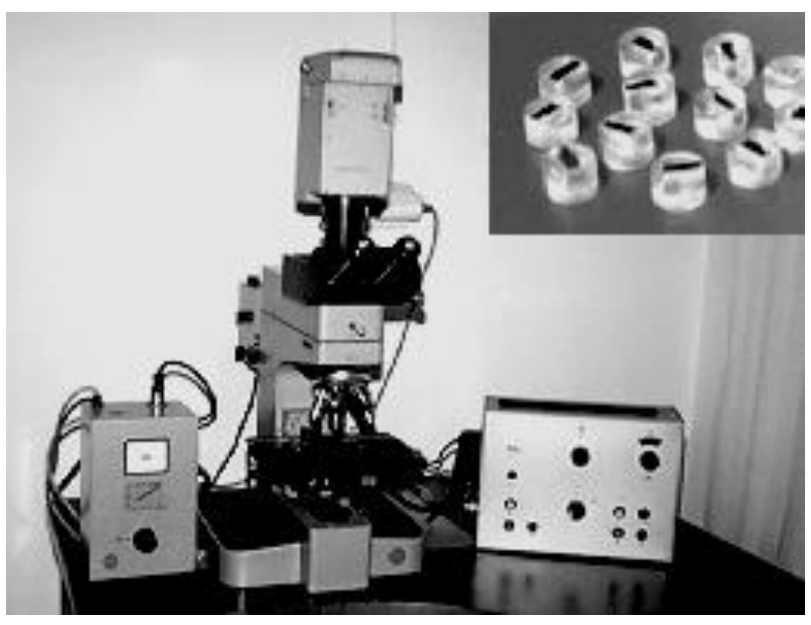

Fig. 6. Aristomet optical microscope with samples 
Surface roughness of the workpiece in the creepfeed grinding process was estimated by measuring a set of surface parameters. The measured parameters were: arithmetic mean deviation of the assessed profile (Roughness Average $R_{a}$ ), mean height value of five local maxima and five local minima (Mean Roughness Depth $R_{z}$ ), maximum height of the profile (Maximum Roughness Depth $R_{\max }$ ) and description of the material portion in the roughness (Profile Bearing Length Ratio $t_{p}$ ). These parameters are the most widely used in surface topography and defined in the specification standard ISO 4287/1. The surface roughness measurements were conducted using the profilometer Form Talysurf made by Taylor Hobson Ltd from UK, Fig.7.

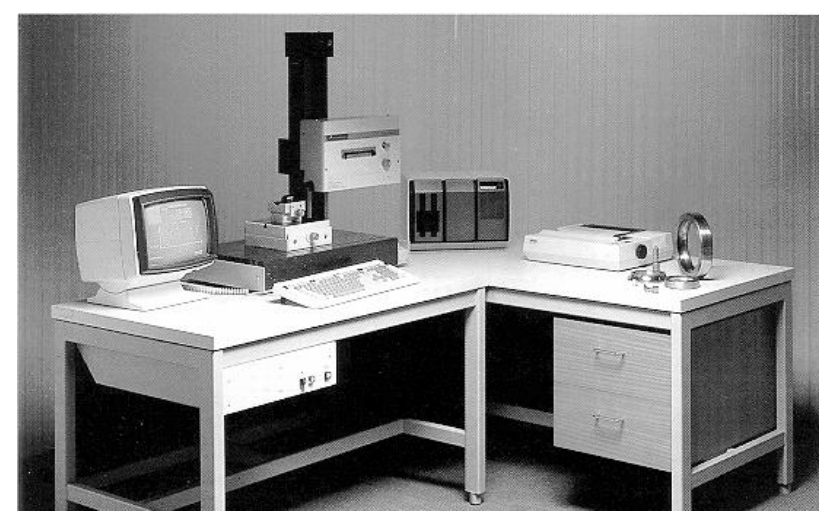

Fig. 7. Form Talysurf profilometer

\section{RESULTS AND ANALYSIS}

It is evident that due to intensive friction between the grinding particles and the workpiece material, an enormous quantity of thermal energy develops in the creep-feed grinding. The increased contribution of the direct-contact thermal energy significantly increases the temperature in the cutting zone. This high cutting temperature has a pronounced negative effect on the grinding wheel, workpiece surface and machine tool. If the temperature thus formed is high enough to cause structural and phase transformations of the workpiece material, the machined surface shall suffer from a number of disadvantages. Should, in addition, low surface roughness appear as well, the overall creep-feed grinding effect can substantially diminish the exploitation properties of the finished product.

\subsection{Surface metallurgy of HSS}

In this study, the surface metallurgy, respectively the heat affected zone of the steel DIN S 2-10-1-8 was assessed by investigation of surface layer properties of the workpiece in the creep-feed grinding, with two grinding wheels.

It was first implemented the metallographic examination of the microstructure. Fig. 8 and 9 show typical photomicrographs of surface layer of the investigated high speed tool steel by the grinding wheel type 32A54 FV BEP and 53A80 F15V PMF, respectively.

The metallographic examinations of the microstructure showed presence of the heat affected zone and recast layer in the creep-feed grinding. The recast layer of a surface machined was presented through uniform representation of the microstructure transformations compared to the bulk material.
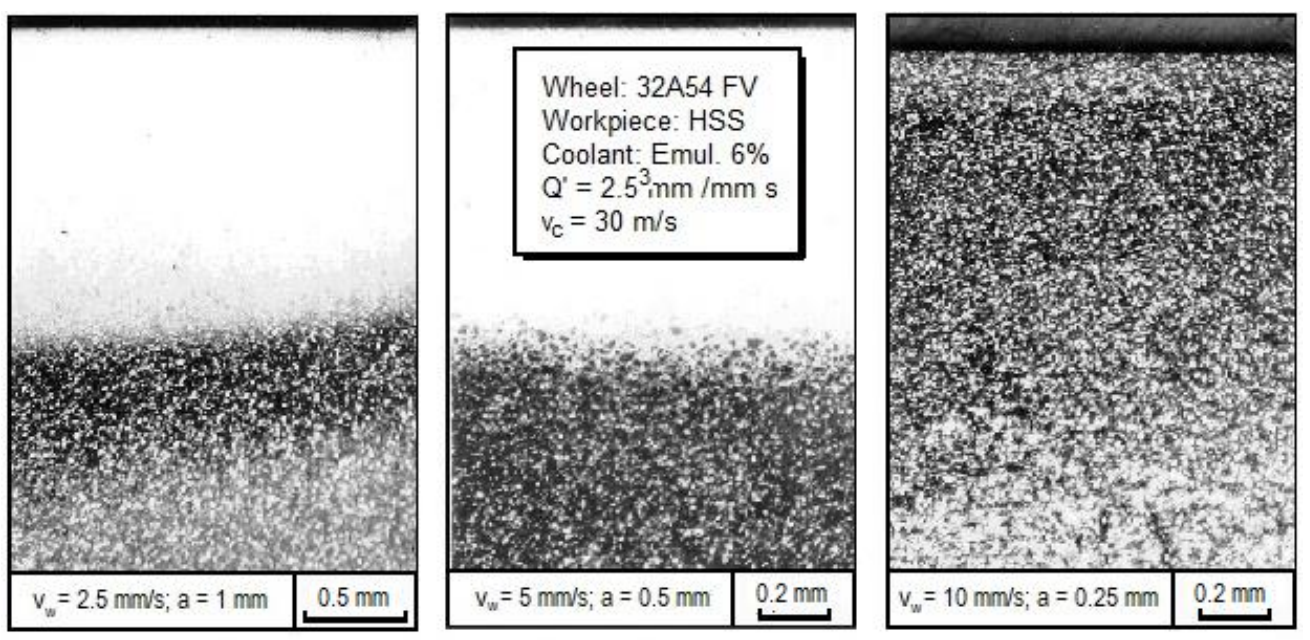

Fig. 8. Typical photomicrographs of surface layer of HSS steel machined with the wheel type 32A54 FV BEP

The analysis of the photomicrographs revealed four characteristic layers: surface hardened layer, interlayer, tempered layer and bulk material,
Fig.10. The secondary hardened layer consists of hardened martensite, residual austenite and carbides. The interlayer consists of martensitic- 
austenitic structure and carbides, where the ratio of the austenite reduces in the direction to the tempered layer. The tempered layer is tempered martensite and carbides, which gradually phase into bulk material consisting of martensite with fine carbides.
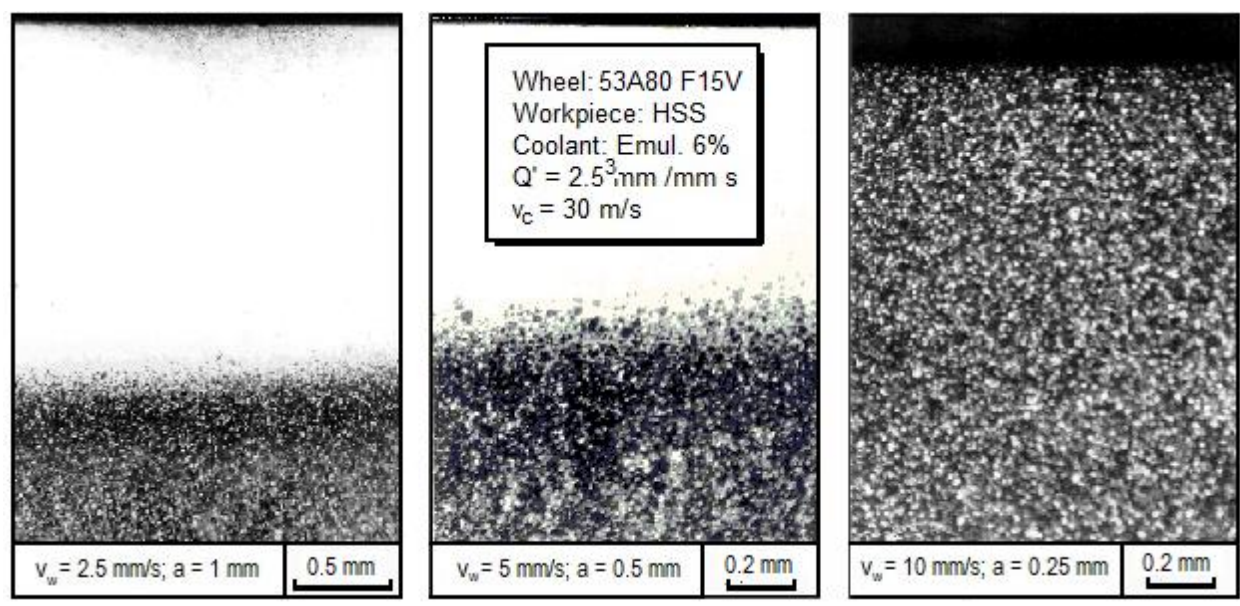

Fig. 9. Typical photomicrographs of surface layer of HSS steel machined with the wheel type 53A80 F15V PMF

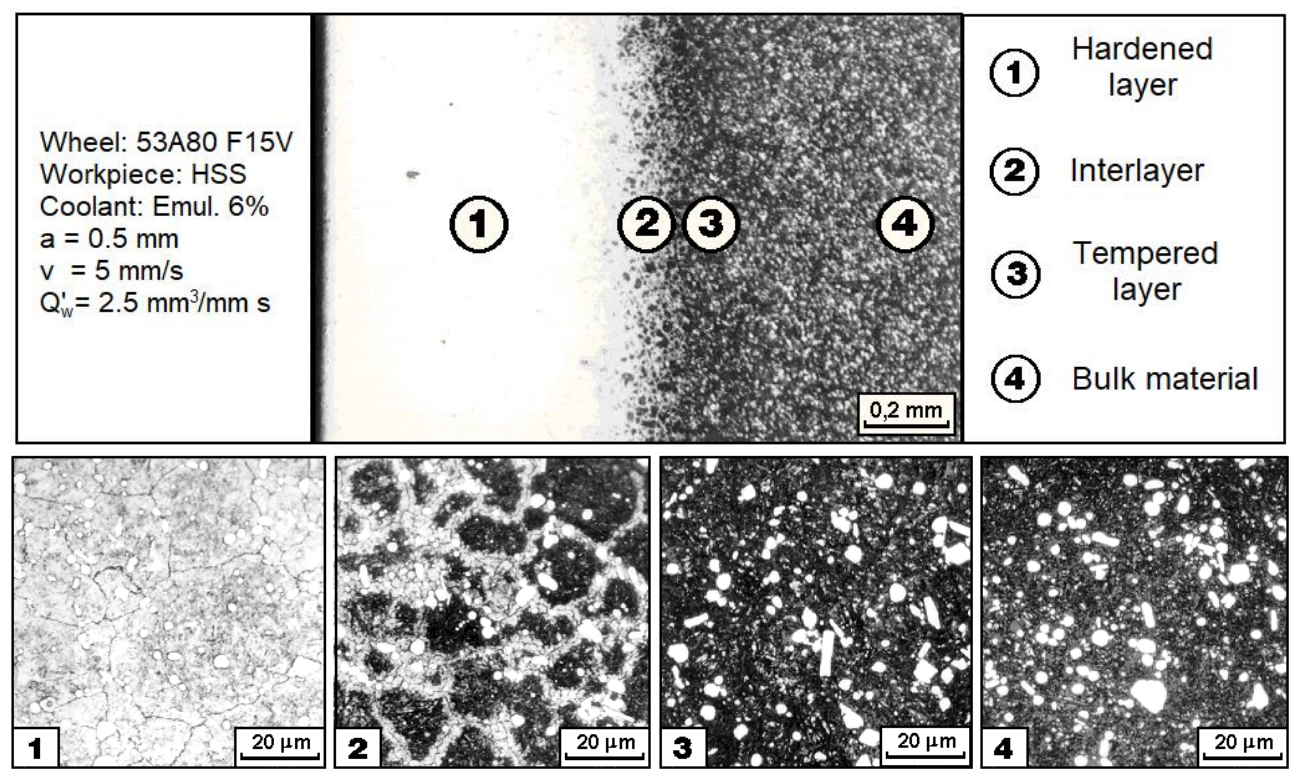

Fig. 10. Microstructure of characteristic surface layer of high speed tool steel in creep-feed grinding

Table 1 shows thickness of the recast layer of the experimental specimens. The metallographic examination showed that thickness of the recast layer appeared in case when the temperature of the cutting zone was higher than the tempered temperature, which is $550{ }^{\circ} \mathrm{C}$ for the high speed tool steel. At the same time, if the cutting temperature does not exceed the transformation temperature which is $723^{\circ} \mathrm{C}$ for the steel that was used in this test, only the tempered layer can be registered. In the opposite case, if the temperature goes beyond $723^{\circ} \mathrm{C}$, multiple layers are registered. In this context, on the basis of metallographic examinations it can be clearly concluded that in creep-feed grinding extremely high cutting temperatures are developed.

Shown in Fig.11 is obtained dependence of the thickness of the recast layer (depth of heat affected zone) on machining conditions of high speed tool steel in creep-feed grinding, for a constant specific material removal rate. It can be seen that the value of the thickness of the recast layer is much higher when the depth of cut is the bigger, and the workpiece feed rate is the lower.

The microhardness measurement on the thickness of the recast layer was performed on a single specimen. Fig.12 shows the photomicrograph of the method of microhardness measurement of high speed tool steel in creepfeed grinding. 
Table 1. Thickness of the recast layer of high speed tool steel in creep-feed grinding

\begin{tabular}{|c|c|c|c|c|c|c|c|}
\hline \multicolumn{3}{|c|}{ Machining conditions } & \multirow[b]{2}{*}{$\begin{array}{l}\text { Specific material } \\
\text { removal rate } \\
Q^{\prime}\left(\mathrm{mm}^{3} / \mathrm{mm} \mathrm{s}^{2}\right.\end{array}$} & \multicolumn{4}{|c|}{ Thickness of the recast layer } \\
\hline $\begin{array}{l}\text { Depth } \\
\text { of cut } \\
a(\mathrm{~mm})\end{array}$ & $\begin{array}{c}\text { Feed } \\
\text { rate } \\
v_{w}(\mathrm{~mm} / \mathrm{s})\end{array}$ & $\begin{array}{c}\text { Wheel } \\
\text { speed } \\
v_{s}(\mathrm{~m} / \mathrm{s})\end{array}$ & & $\begin{array}{c}\text { Hardened } \\
\text { layer } \\
(\mathrm{mm})\end{array}$ & $\begin{array}{l}\text { Interlayer } \\
(\mathrm{mm})\end{array}$ & $\begin{array}{c}\text { Tempered } \\
\text { layer } \\
(\mathrm{mm})\end{array}$ & $\begin{array}{l}\text { Recast } \\
\text { layer } \\
(\mathrm{mm})\end{array}$ \\
\hline \multicolumn{8}{|c|}{ Norton grinding wheel type 32A54 FV BEP } \\
\hline 0.05 & 50 & \multirow{5}{*}{30} & \multirow{5}{*}{2.5} & \multicolumn{4}{|c|}{ Without a recast layer } \\
\hline 0.1 & 25 & & & \multicolumn{4}{|c|}{ Without a recast layer } \\
\hline 0.25 & 10 & & & - & - & 0.2 & 0.2 \\
\hline 0.5 & 5 & & & 0.7 & 0.15 & 0.3 & 1.15 \\
\hline 1 & 2.5 & & & 1.2 & 0.6 & 0.8 & 2.6 \\
\hline \multicolumn{8}{|c|}{ Winterthur grinding wheel type 53A80 F15V PMF } \\
\hline 0.25 & 10 & \multirow{3}{*}{30} & \multirow{3}{*}{2.5} & 0.4 & 0.15 & - & 0.55 \\
\hline 0.5 & 5 & & & 0.75 & 0.2 & 0.5 & 1.45 \\
\hline 1 & 2.5 & & & 1.4 & 0.4 & 1 & 2.8 \\
\hline
\end{tabular}

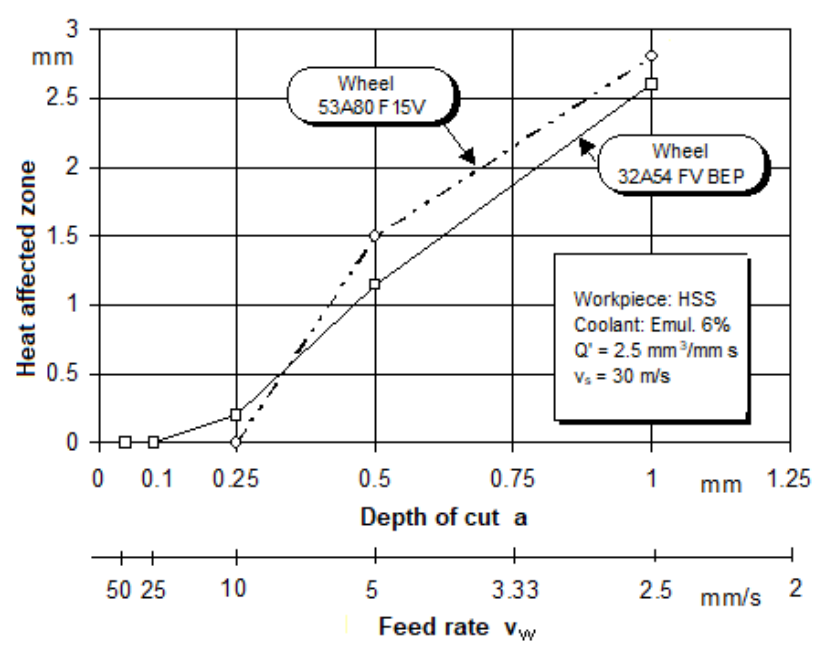

Fig. 11. Dependence of heat affected zone on the machining conditions of HSS steel in creep-feed grinding

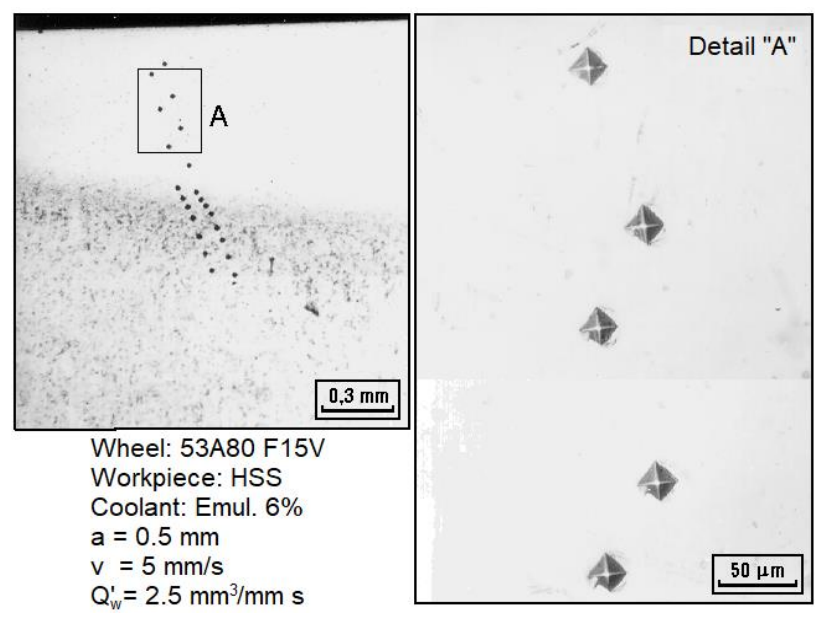

Fig. 12. Photomicrograph of microhardness measurement

Fig.13 shows the diagram of change of microhardness on thickness of the surface layer in creep-feed grinding.
The measured microhardness indicates that the hardness of the hardened layer ( $965.4 \mathrm{HV}$ ) is somewhat higher than the hardness of the bulk material (904.5 HV). The smallest measured value of the hardness is found in the tempered layer (842.3 HV) of the steel DIN S 2-10-1-8.

The higher hardness of the hardened layer was the result of the fine-grained austenitic-martensitic structure, while the lower hardness of the tempered layer occurred in the martensitic-austenitic phase transformation of high speed tool steel.

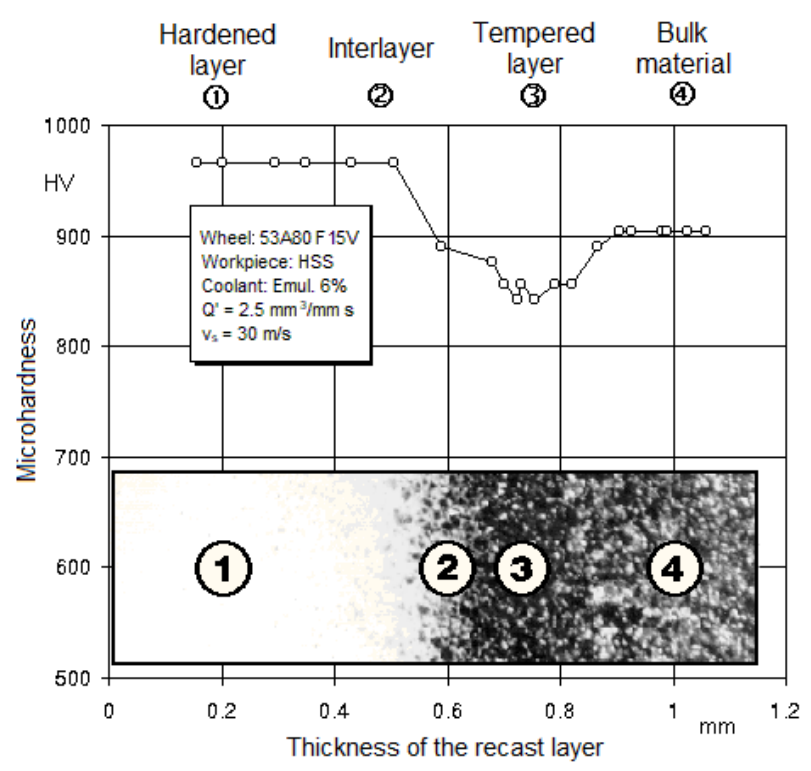

Fig. 13. Dependence of microhardness on depth of the surface layer in creep-feed grinding

During the further inspection of the workpiece material surface layer condition, not one specimen was found with cracks.

On the other hand, burns were noticed in all specimens where is present the heat affected zone and recast layer. Fig.14 and 15 show images of the 
workpiece surface of the investigated high speed tool steel after the creep-feed grinding by wheel type 32A54 FV BEP and 53A80 F15V PMF, respectively.
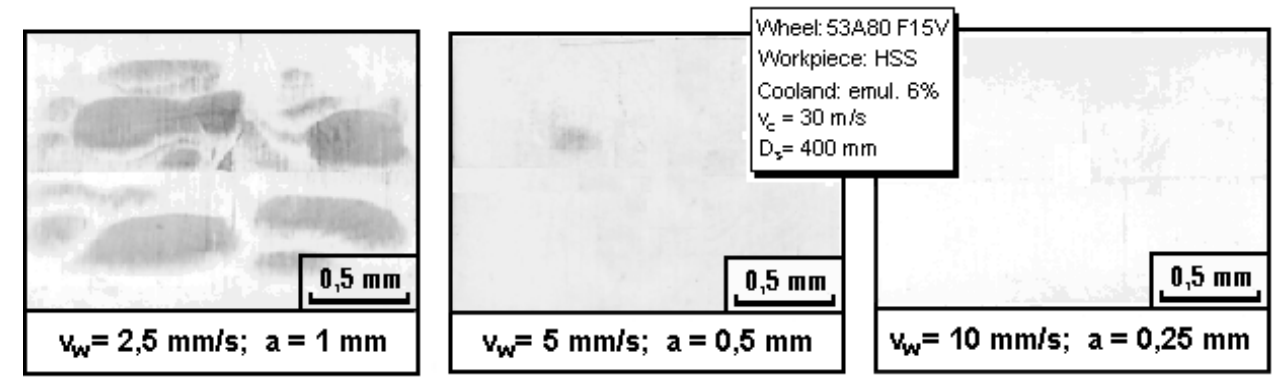

Fig. 14. Images of the workpiece surface of HSS steel machined with the wheel type 32 A54 FV BEP
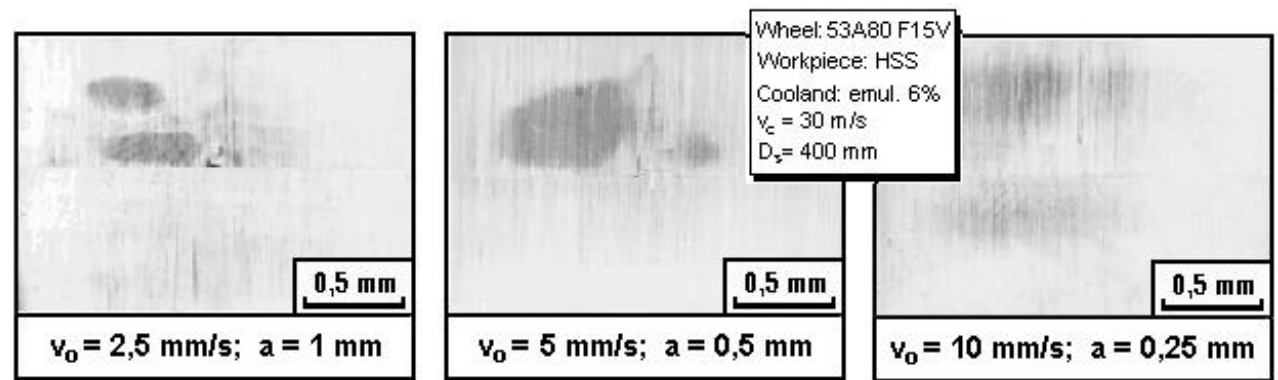

Fig. 15. Images of the workpiece surface of HSS steel machined with the wheel type 53A80 F15V PMF

\subsection{Surface roughness of HSS}

The purpose of this study was to identify the influence of creep-feed grinding process on surface roughness. For that purpose, a set of surface roughness parameters under various machining conditions were determined for high speed tool steel by the grinding wheel type 32A54 FV BEP and 53A80 F15V PMF. The surface roughness was measured in multiple places on the machined surface of a workpiece.

In Fig.16 is shown experimentally obtained dependence of the surface roughness parameters (roughness average $\mathrm{Ra}$, mean roughness depth $\mathrm{Rz}$, maximum roughness depth $\mathrm{Rmax}$ and profile bearing length ratio tp) on the depth of cut and feed rate for a constant specific material removal rate.

The increase of the surface roughness with increasing the depth of cut is present because of increased chip thickness and higher friction in the workpiece cutting zone. On the other hand, when the workpiece feed rate is increasing, due to the decrease of the contact time, the surface roughness is decreasing. The diagrams show that there exists an optimal specific material removal rate which results in minimum possible surface roughness. By all means, it is evident that creepfeed grinding process gives an excellent surface roughness.
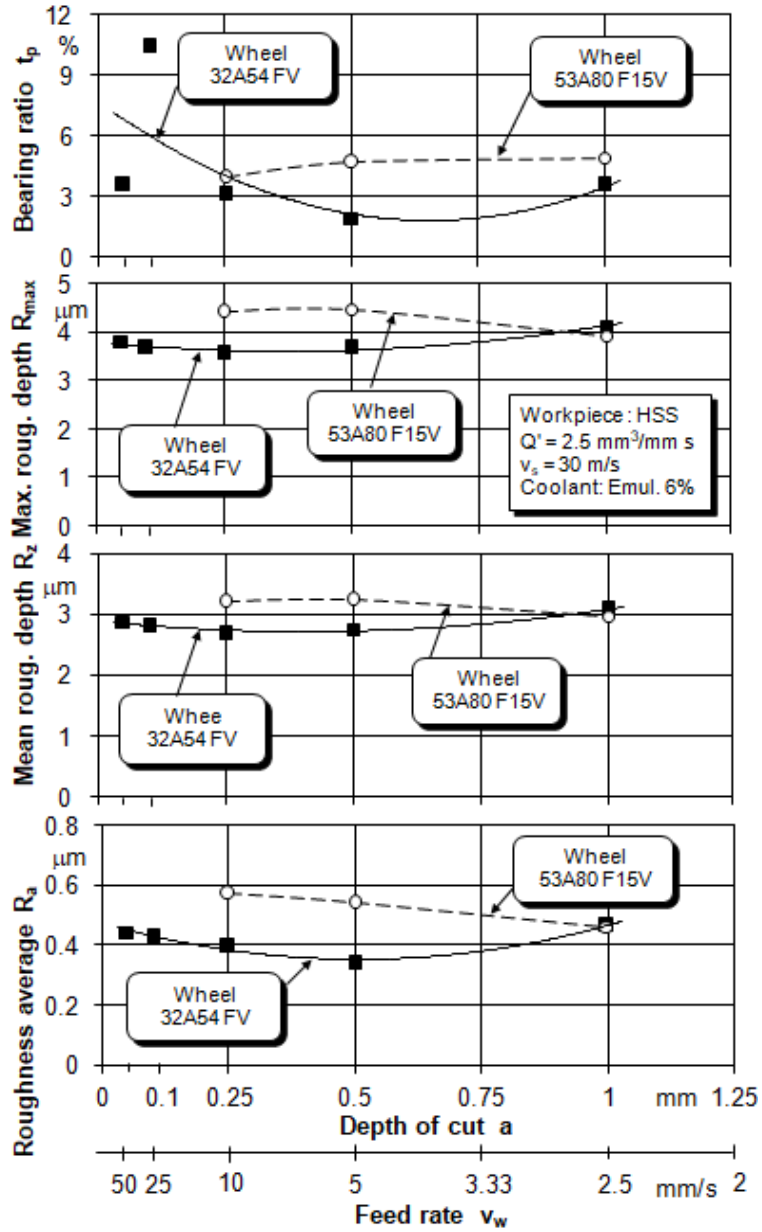

Fig. 16. Dependence of surface roughness parameters on machining conditions of HSS steel in creep-feed grinding for a constant specific material removal rate 


\section{CONCLUSIONS}

With the rapidly growing trends in terms of productivity and surface quality, the highperformance grinding process is becoming an important segment of the manufacturing industry. The creep-feed grinding is an advanced abrasive process widely used in machining complex engineering products made from difficult-tomachine materials. However, the creep-feed grinding leads to a more intense development of thermal energy in the cutting zone, which is why special attention is focused on surface integrity.

The unwanted heat affected zone and recast layer in the workpiece material was detected in almost all cases the creep-feed grinding. Metallurgical changes were detected in all cases when the cutting temperature was higher than tempering temperature. Thickness of the recast layer is in direct proportion with the machining conditions. It can be seen that the recast layer is higher when the depth of cut is bigger, i.e. when the workpiece feed rate is lower. Compared to the microhardness of the bulk material, hardness of the hardened layer was slightly higher, while the hardness of the tempered layer was lower. As regards, the burns appeared in all cases when the heat affected zone is present. On the other hand, the cracks were not noticed.

Related to experimental study of the surface roughness, it follows that in the creep-feed grinding exists an optimal machining condition which results in very good surface. Increasing the depth of cut leads to a slight increase of surface roughness, while with decreasing the workpiece feed rate the surface roughness is increasing. Generally, the creep-feed grinding process impress that workpiece has a glossy surface topography.

\section{ACKNOWLEDGEMENTS}

The paper is the result of the research within the project financed by the Ministry of Education, Science and Technological Development of the Republic of Serbia.

\section{REFERENCES}

[1] R.V. Rao, Advanced modeling and optimization of manufacturing processes. Springer, London, 2011.

https://doi.org/10.1007/978-0-85729-015-1
[2] X.L. Shi, S.C. Xiu, H.L. Su, Residual stress model of pre-stressed dry grinding considering coupling of thermal, stress, and phase transformation. Advances in Manufacturing, 7, 2019: 401-410.

https://doi.org/10.1007/s40436-019-00280-3

[3] M. Gostimirovic, M. Sekulic, D. Rodic, Thermal study of the creep-feed grinding - A review. Journal of Production Engineering, 23 (1), 2020: 1-10.

http://doi.org/10.24867/JPE-2020-01-001

[4] Q. Miao, W. Ding, W. Kuang, J. Xu, Tool wear of vitrified microcrystalline alumina wheels in creep feed profile grinding of turbine blade root of single crystal nickel-based superalloy. Tribology International, 145, 2020: 106144. https://doi.org/10.1016/i.triboint.2019.10614 4

[5] P. Kovac, M. Gostimirovic, Grinding force of cylindrical and creep-feed grinding modelling, In book: Abrasive Technology-Characteristics and Applications. IntechOpen, 4, 2018: 65-82.

https://doi.org/10.5772/intechopen.76968

[6] J. Kopac, P. Krajnik, High-performance grinding - A review. Journal of Materials Processing Technology, 175 (1-3), 2006: 278-284.

https://doi.org/10.1016/i.jmatprotec.2005.04. $\underline{010}$

[7] V.T. Thang, N.A. Tuan, N.V. Tiep, Evaluation of grinding wheel wear in wet profile grinding for the groove of the ball bearing's inner ring by pneumatic probes. Journal of Mechanical Science and Technology, 32 (3), 2018:12971305.

https://doi.org/10.1007/s12206-018-0234-5

[8] M. Gostimirovic, P. Kovac, D. Jesic, B. Skoric, B. Savkovic, Surface layer properties of the workpiece material in high performance grinding. Metalurgija, 51 (1), 2012: 105-108

[9] P. Krajnik, J. Kopac, A. Sluga, Design of grinding factors based on response surface methodology. Journal of Materials Processing Technology, 162, 2005: 629-636.

https://doi.org/10.1016/j.jmatprotec.2005.02. $\underline{187}$

[10] J.S. Kim, J.D. Hwang, Y.G. Jung, Development of twin wheel creep-feed grinding machine using continuous dressing for machining of aircraft rotary wing. Journal of Central South University of Technology, 18 (3) 2011: 704710. 
https://doi.org/10.1007/s11771-011-0751-1

[11] M.K. Sinha, S. Ghosh, V.R. Paruchuri, Modelling of specific grinding energy for Inconel 718 superalloy. Proceedings of the Institution of Mechanical Engineers, Part B: Journal of Engineering Manufacture, 233 (2), 2019: 443-460.

\section{https://doi.org/10.1177/0954405417741513}

[12] M. Gostimirovic, M. Radovanovic, M. Madic, D. Rodic, N. Kulundzic, Inverse electro-thermal analysis of the material removal mechanism in electrical discharge machining. The International Journal of Advanced Manufacturing Technology, 97 (5-8), 2018: 1861-1871.

https://doi.org/10.1007/s00170-018-2074-y

[13] R.L. Hecker, S.Y. Liang, Predictive modeling of surface roughness in grinding. The International Journal of Machine Tools and Manufacture, 43 (8), 2003: 755-761.

https://doi.org/10.1016/S08906955(03)00055-5

[14] D. Golubovic, P. Kovac, B. Savkovic, D. Jesic, M. Gostimirovic, Testing the tribological characteristics of nodular cast iron austempered by a conventional and an isothermal procedure, Materiali in tehnologije, 48 (2), 2014: 293- 298.

[15] B. Li, Q. Miao, M. Li, X. Zhang, W. Ding, An investigation on machined surface quality and tool wear during creep feed grinding of powder metallurgy nickel-based superalloy FGH96 with alumina abrasive wheels. Advances in Manufacturing, 8, 2020: 160-176. https://doi.org/10.1007/s40436-020-00305-2

[16] X. Zhou, F. Xi, Modeling and predicting surface roughness of the grinding process. The International Journal of Machine Tools and Manufacture, 42 (8), 2002: 969-977.

https://doi.org/10.1016/S08906955(02)00011-1
[17] M. Gostimirović, D. Rodić, P. Kovač, D. Ješić, N. Kulundžić, Investigation of the cutting forces in creep-feed surface grinding process. Journal of Production Engineering, 18 (2), 2015: 21-24.

[18] S. Guo, S. Malkin, Analytical and experimental investigation of burnout in creep-feed grinding. CIRP Annals - Manufacturing Technology, 43, 1994: 283-286.

https://doi.org/10.1016/S00078506(07)62214-8

[19] I. Mankova, M. Vrabel, J. Beno, P. Kovac, M. Gostimirovic, Application of Taguchi method and surface response methodology to evaluate of mathematical models for chip deformation when drilling with coated and uncoated twist drills. Manufacturing Technology, 13 (4), 2013: 492-499.

https://doi.org/10.21062/ujep/x.2013/a/1213 $-2489 / \mathrm{MT} / 13 / 4 / 492$

[20] N. Ortega, H. Bravo, I. Pombo, J.A. Sanchez, G. Vidala, Thermal Analysis of Creep Feed Grinding. Procedia Engineering, 132, 2015: 1061-1068.

https://doi.org/10.1016/i.proeng.2015.12.596

[21] M. Gostimirovic, M. Sekulic, J. Kopac, P. Kovac, Optimal control of workpiece thermal state in creep-feed grinding using inverse heat conduction analysis. Strojniski vestnik - Journal of mechanical Engineering, 57 (10), 2011: 730738.

https://doi.org/10.5545/sv-jme.2010.075

[22] X.L. Shi, S.C. Xiu, L. Dong, Study of prestressed dry grinding and its integrated hardening model of hardening layer. The International Journal of Advanced Manufacturing Technology, 95 (5/8), 2018:2529-2541.

https://doi.org/10.1007/s00170-017-1386-7 